\title{
Asparagus tamariscinus (Asparagaceae Juss.) - is a promising species for vertical greenery
}

\author{
Anatoly Karakulov ${ }^{1, *}$, Alexander Tashev ${ }^{2}$ \\ ${ }^{1}$ Central Siberian Botanical Garden of the SB RAS, 630090 Novosibirsk, Russia \\ ${ }^{2}$ University of Forestry, 1113, Sofia, Bulgaria
}

\begin{abstract}
Use of vertical greenery techniques for decorating hedges, walls of buildings and constructions, which allows to reduce the noise level, is hampered by an insufficient assortment of plants suitable for cultivation outdoors in Siberia and the Russian Far East. Asparagus tamariscinus, a high decorative, winter-hardy, and drought-resistant herbaceous polycarpicus, is a promising species that can fill this gap.
\end{abstract}

The techniques of vertical greenery in landscape design, which make it possible to decorate hedges, walls of buildings and structures and reduce noise, are widely used in areas with a mild climate. In addition to tropical and subtropical regions, these are Western and Central Europe, North America [1, 2], and in our country they are the Southern, North Caucasian, Central, Northwest and Volga federal areas [3, 4, 5, 6, 7].

In urban plantings in Siberia, there is a clear lack of plants for vertical greening [8, 9, $10,11]$. The species that are currently in use are usually not hardy enough. Special agricultural technology, shelters for winter, lifting plants on supports or laborious pruning in spring are required.

There are very few stable species and forms that develop a beautiful magnificent crown over a short Siberian summer. A winter-hardy and drought-tolerant species, Asparagus tamariscinus, would help to.

Previously, this species has never been introduced in the botanical gardens of Siberia. Asparagus officinalis L., was long known in cultivacion. It has many cultivars for food and decorative purposes. A large number of species of the genus Asparagus are used as indoor and greenhouse plants.

Asparagus tamariscinus Ivanova ex Grubov (Fig. 1) is a herbaceous rhizome polycarpic, with white-membranous sinuous shoots reaching $1.5 \mathrm{~m}$ in height [12].

The branches extend at an obtuse (less often right) angle, are smooth angular, with a bluish bloom, the branches of the second order are downward deflected. Cladodes, $8-10$ (12) in the bunch, slightly exceed the length of the internodes, widely spread, of unequal length, curved, rough or almost smooth, thick. Leaves with a long and sharp spur.

Pedicels are 7 - 16 (20) $\mathrm{mm}$ long, articulated $1.5-2.5 \mathrm{~mm}$ below the base of the flower. Anthers are oblong, longer than or equal to threads. Berries are dark red, 3-4 $\mathrm{mm}$ in diameter, according to published data 5-7 mm [13, 14] (Fig. 2). In natural habitats it grows

* Corresponding author: krk@inbox.ru 
along the banks of rivers and irrigation ditches in the desert and desert-steppe zones, in thickets of shrubs

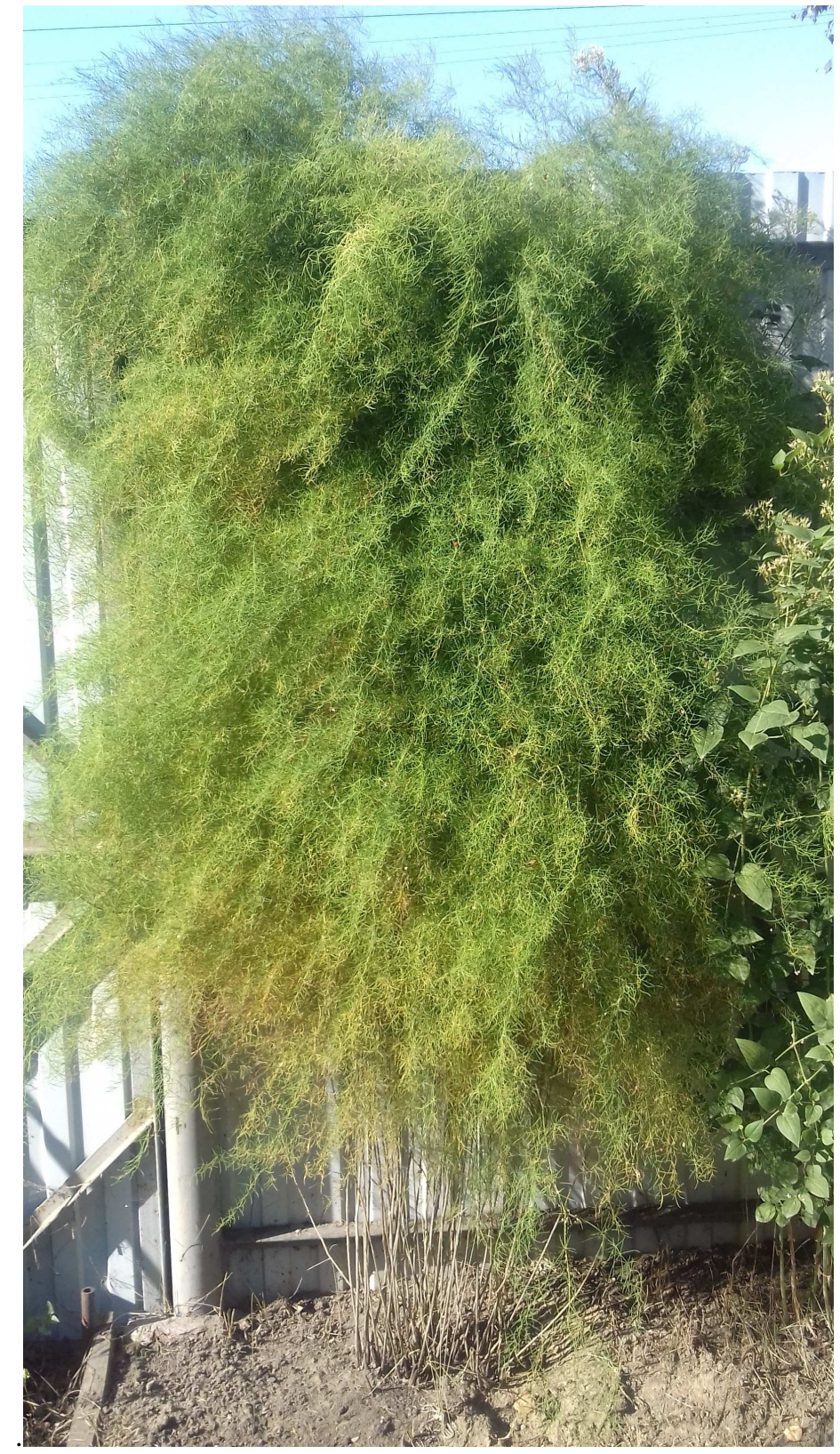

Fig. 1. Asparagus tamariscinus on a trellis.

Live plants and seeds were collected by us in a dry floodplain of the Shemi River, Republic of Tuva, Dzun - Khemchik Region (51.252354 N, 91.190042 E). Asparagus seedlings were planted in outdoors and cultivated with minimal use of agricultural techniques which consisted only in timely weeding and installation of trellis. Seeds, after preliminary soaking and germination, were sown in outdoors in mid-May. The agricultural 
technique for growing Asparagus tamariscinus seedlings is similar to that for Asparagus officinalis $[15,16]$.

Under conditions of introduction, Asparagus tamariscinus develops a dense, lush crown over a short period of time. Regrowth of shoots begins in early spring, as soon as snow melts and the topsoil warms up a bit. In the conditions of Novosibirsk, this happens in late April, early May. Shoots grow very quickly, $15-20 \mathrm{~cm}$ per a day. By the end of May, growth ends. Plants in culture reach a height of $3-3.5 \mathrm{~m}$, with a crown diameter of about 1 $\mathrm{m}$ (at 10 years of age).

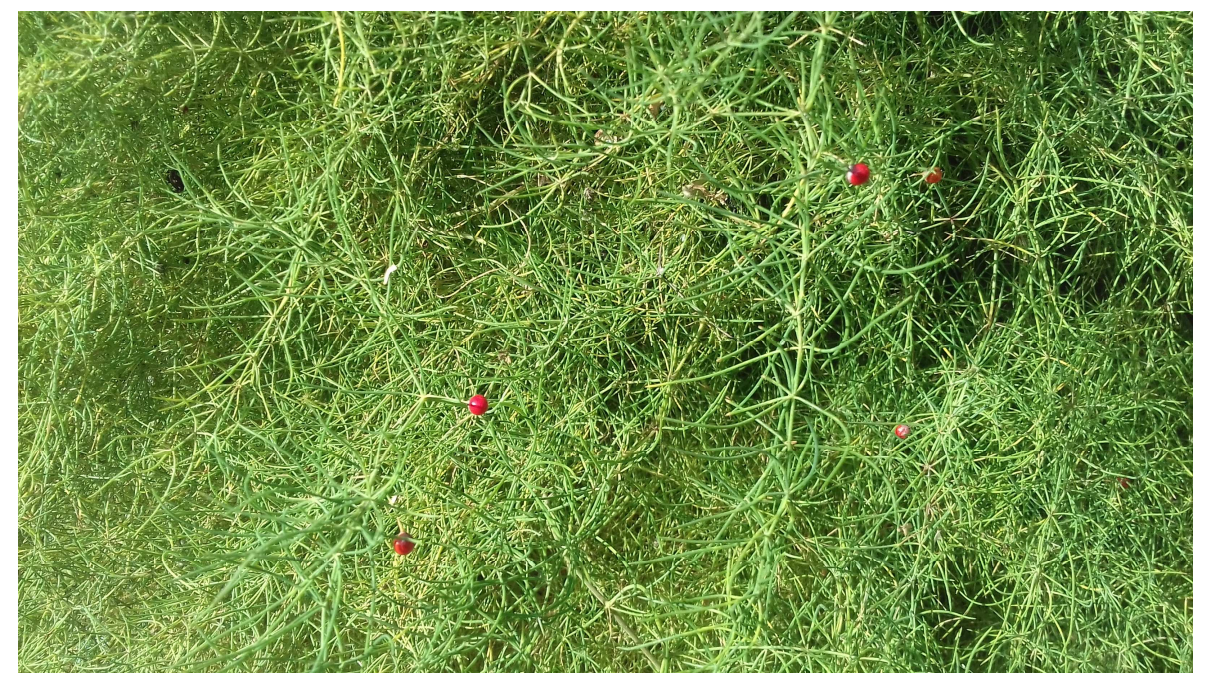

Fig. 2. The fruits of Asparagus tamariscinus.

Crown is very dense, lush and delicate. Flowering begins in late June, and the fruits ripen in late August. In September, the plants turn yellow, remaining decorative until snow falls. Cladodes fly around with the establishment of negative temperatures. At this time, the shoots are cut. The rhizomes of Asparagus tamariscinus hibernate without any shelter, even in places where snow does not linger.

Asparagus tamariscinus proved to be an unpretentious and hardy species, rapidly growing in the spring in the conditions of introduction in the Central Siberian Botanical Garden of the SB RAS, Novosibirsk. The species is high decorative and is recommended for use in vertical greenery in Siberia and the Russian Far East.

\section{References}

1. P. Blanc, The Vertical Garden. From nature to the city, Revised and updated (W.W. Norton \& Company, New York, London, 2012)

2. N. Vialard, Gardening vertically. 24 ideas for creating your own green walls (W.W. Norton \& Company, New York, London, 2012)

3. Andrushko T., Bulletin of the Saratov State Agrarian University. N.I. Vavilova 11 (2010)

4. E. Matvienko, Ornamental plants in vertical landscaping, Proceedings Problems and prospects of the development of land reclamation and forestry in the Southern Federal District of the international scientific-practical conference dedicated to the 90th 
anniversary of higher forest education in the Don region, Novocherkassk, 08-10 Dec. (2010)

5. E. Gorokhova, N. Yurtaeva, Study of the assortment of plants for creating vertical gardens for the street landscape, Materials of the XI scientific-practical conference, Landscape architecture and ecology, Nizhny Novgorod, March 31 (2015)

6. O. A. Erokhova, Assortment of woody-herbaceous vines for use in vertical gardening in Veliky Novgorod, Landscape architecture, construction and woodworking, St. Petersburg, February 15-16 (2018)

7. M. Zakrevskaya, M. Nagaitseva, L. Melnik, A. Peshkova, L. Kirillova, N. Zhukov., Ural Scientific Herald, 7-5 (2019)

8. E. Kartashova, Vertical gardening of the Emerald Park in the city of Barnaul, Contribution of young scientists to agricultural science, Samara, April 13-14 (2016)

9. A. Bukhryakova, O. Smolina, Study of the possibility of using the vertical landscape of the facades of buildings and structures in Novosibirsk, Collection of materials of the 28th All-Russian scientific-practical conference on graphic information technologies and systems, Nizhny Novgorod, April 16-19, (2018)

10. E. Kurlovich, O. Stupakova, T. Aksyanova, To the question of vertical landscaping of Siberian cities, All-Russian Scientific and Practical Conference, Technologies and equipment for design, planning and construction of parks and gardens, Krasnoyarsk, December 20 (2019)

11. M. Sedayeva, Woody plants for vertical gardening in Krasnoyarsk, All-Russian scientific-practical conference, Technologies and equipment for design, planning and construction of parks and gardens, Krasnoyarsk, December 20 (2019)

12. Key to plants of the Republic of Tuva (Novosibirsk, Publishing House of the SB RAS, 2007)

13. N. Vlasova, Asparagus of Siberia Science (Novosibirsk, Siberian Branch, 1989)

14. Flora of Siberia Araceae - Orchidaceae. (Novosibirsk, Nauka, 1987)

15. E. Vasfilova, T. Vorobyova, Population ecology and plant introduction. (Yekaterinburg, 2003)

16. Yu. Shevchenko, I. Ushakova, E. Kurbakov, L. Bespalko, V. Kharchenko. Vegetables of Russia, 5 (2018) 